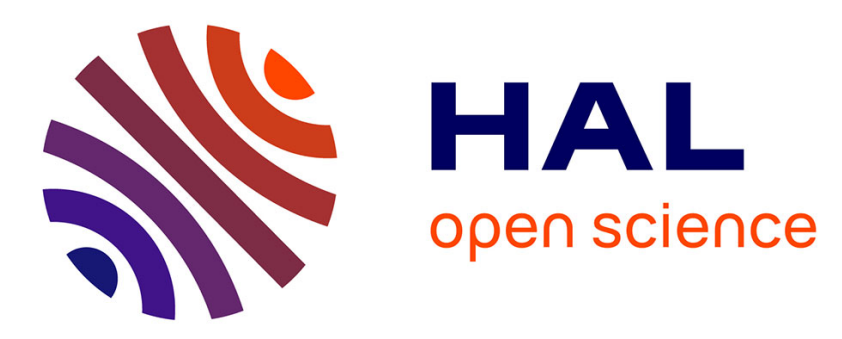

\title{
Flexible and conductive multilayer films based on the assembly of PEDOT:PSS and water soluble polythiophenes
}

Florian Jurin, Cédric C Buron, Sébastien Clément, Ahmad Mehdi, Lydie Viau, Boris Lakard, Martin Nicolas, Claudine Filiatre

\section{To cite this version:}

Florian Jurin, Cédric C Buron, Sébastien Clément, Ahmad Mehdi, Lydie Viau, et al.. Flexible and conductive multilayer films based on the assembly of PEDOT:PSS and water soluble polythiophenes. Organic Electronics, 2017, 46, pp.263-269. 10.1016/j.orgel.2017.04.013 . hal-01518610

\author{
HAL Id: hal-01518610 \\ https://hal.science/hal-01518610
}

Submitted on 27 Jan 2022

HAL is a multi-disciplinary open access archive for the deposit and dissemination of scientific research documents, whether they are published or not. The documents may come from teaching and research institutions in France or abroad, or from public or private research centers.
L'archive ouverte pluridisciplinaire HAL, est destinée au dépôt et à la diffusion de documents scientifiques de niveau recherche, publiés ou non, émanant des établissements d'enseignement et de recherche français ou étrangers, des laboratoires publics ou privés. 


\title{
Flexible and conductive multilayer films based on the assembly of PEDOT:PSS and water soluble polythiophenes.
}

\author{
F. E. Jurin ${ }^{1}$, C.C. Buron ${ }^{1} *$, S. Clément ${ }^{2}$, A. Mehdi ${ }^{2}$, L. Viau ${ }^{1}$, B. Lakard ${ }^{1}$. N. Martin ${ }^{3}$, C. Filiâtre ${ }^{1}$ \\ ${ }^{1}$ Institut UTINAM - UMR 6213 - CNRS - Univ. Bourgogne Franche-Comté \\ 16, Route de Gray, 25030 Besançon Cedex, France \\ ${ }^{2}$ Institut Charles Gerhardt Montpellier (ICGM), UMR 5253, CNRS-UM-ENSCM, Université de Montpellier, \\ Bâtiment 17, CC 1701, Place E. Bataillon, 34095 Montpellier Cedex 5, France \\ ${ }^{3}$ Institut FEMTO-ST, UMR 6174 - CNRS - Univ. Bourgogne Franche-Comté \\ 15B, Avenue des Montboucons, 25030 Besançon Cedex, France
}

* Corresponding author. Tel.: +33 38159 25; E-mail address: cedric.buron@ @univ-fcomte.fr.

\begin{abstract}
Flexible conductive polyelectrolyte multilayer films built upon anionic poly(3,4ethylenedioxythiophene):polystyrene sulfonate (PEDOT:PSS) and cationic poly(3hexylthiophene)-based conjugated polyelectrolytes (P3HT-R) containing imidazolium, pyridinium and phosphonium ionic groups were prepared using electrostatic layer-by-layer assembly. Adsorbed amount of each polyelectrolyte strongly increases when divalent cations $\left(\mathrm{Ba}^{2+}\right)$ are employed as electrolyte and when the rinsing step is avoided during the build-up. The electrical properties of these (P3HT-R/PEDOT:PSS $)_{n}$ multilayer films were then

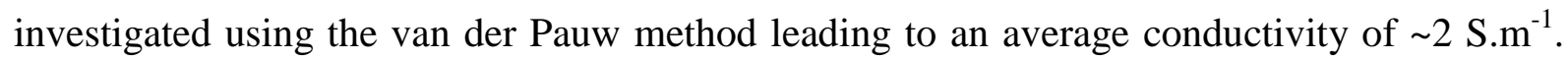
Semiconducting behavior of these organic coatings was demonstrated by the direct relationship between the conductivity and the temperature. (P3HT-R/PEDOT:PSS $)_{n}$ multilayer films exhibited p-type semiconducting behavior as showed by Seebeck measurements. Finally, these films were successfully deposited onto flexible polymer sheets and their conductivity was found to be not affected by applying a bending stress.
\end{abstract}

Keywords : Conductive polyelectrolyte multilayer, Layer-by-layer, P3HT-based conjugated polyelectrolyte, PEDOT:PSS, Seebeck effect. 


\section{Introduction}

$\pi$-conjugated polyelectrolytes (CPEs) have been the subject of tremendous interest in the recent years as they combine the semiconducting properties of conjugated polymers with charge-mediated behavior of polyelectrolytes, thanks to their $\pi$-conjugated backbone and ionic side chains[1]. Compared to neutral conjugated polymers, CPEs are soluble in polar solvents such as water and methanol, which allows their use in a wide range of applications such as biological sensors[2, 3], biomedical imaging[4, 5], photovoltaic cells[6] and organic light-emitting devices[7, 8]. Since the conformation of the polymer backbone directly influences the optoelectronic properties of CPEs, understanding and developing self-assembly strategies to control the CPE conformation is of crucial importance[9, 10].

Self-assembly is an elegant approach for obtaining conjugated polymer nanostructures with defined orientation and size[10, 11]. In the case of CPEs, their inherent amphilicity enables their self-assembly into ordered aggregates in both solution and solid phases[12-14]. Their self-assembly may also be manipulated by combining them with oppositely charged substances such as metal ions and complexes[15-18], DNA[19, 20], surfactants[21-23] and polymers[24] for building complex supramolecular structures. In this respect, electrostatic layer-by-layer $(\mathrm{LbL})$ deposition process based on the sequential adsorption of oppositely charged species represents an easy and convenient strategy for obtaining CPE films with controlled composition, architecture and properties at the nanometer scale[25, 26]. Such LbLbased deposited CPE films can be exploited into organic electronics as components of organic light-emitting devices[27, 28] and polymer solar cells[29-31].

Polythiophenes-based CPEs have emerged as a fascinating class of materials for organic electronics due to their high conductivity, stability and processability[32-34]. In addition, the availability of robust synthetic protocols (e.g. Kumada catalyst transfer polycondensation[3537]), allows the preparation of multiple polymer topographies (homopolymers, random/block 
copolymers) with a high degree of control over the final structure and molecular weight. The first LbL self-assembly of polythiophene-based CPEs was reported by McCullough et al. leading to structurally ordered nano-layered sheets of conducting polymers exhibiting electrical conductivities of 0.04 S.cm ${ }^{-1} \cdot{ }^{[38]}$ More recently, Buriak's group combined a cationic pyridinium-based poly(3-hexylthiophene) (P3HT) CPE (P3HT-R) with a colloidal suspension of poly(3,4-ethylenedioxy thiophene):polystyrene sulfonate (PEDOT:PSS) through a LbL assembly process for inverted polymer solar cell device[29, 30], allowing to improve the filmforming property and stability of CPEs.

In this present work, we examined a broader array of CPEs based on a common polythiophene backbone, but bearing different ionic end groups (P3HT-R): poly(3-[N-(1methylimidazolium-3-yl)hexyl]-thiophene-2,5-diyl)] (P3HT-Im), $\operatorname{poly}\left(3-\left[6^{\prime}-\right.\right.$ trimethylammonium)hexyl]-thiophene-2,5-diyl] (P3HT-NMe3) and poly(3-[6'trimethylphosphonium)hexyl]-thiophene-2,5-diyl] (P3HT-PMe3) (Scheme 1). The growth of the electrostatic LbL films based on these cationic P3HT-R and the colloidal suspension of anionic PEDOT:PSS were investigated using a combination of in situ optical reflectometry, profilometry and atomic force microscopy (AFM). The electrical properties of these polyelectrolyte multilayers films deposited onto rigid and flexible substrates were then evaluated by van der Pauw method and Seebeck experiments. It was in particular showed that their conductivity is not modified by applying a bending stress onto the polymer flexible substrate. 


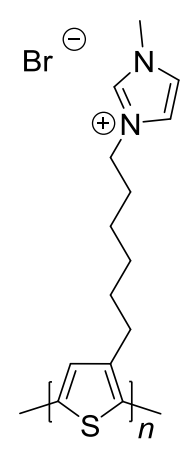

P3HT-Im

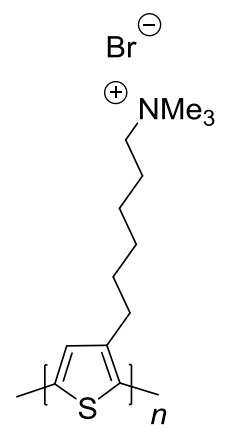

P3HT-NMe 3

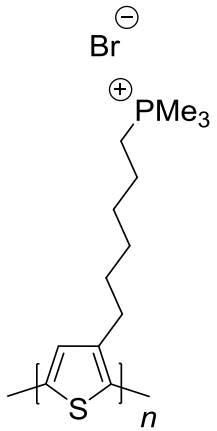

P3HT-PMe 3

Scheme 1: Chemical structures of the employed polythiophene-based conjugated polyelectrolytes P3HT-R.

\section{Experimental Section}

\section{Chemicals and materials.}

Cationic polythiophenes were synthesized as previously reported[20]. First, a Kumada catalyst-transfer polycondensation (KCTP)[39] was used to prepare the regioregular head-totail bromide-bearing polythiophene precursor polymer (P3HT-Br). The number-averaged molecular weight $\left(M_{n}\right)$ was determined by SEC analysis $\left(M_{n} \sim 13500\right.$ g.mol $\left.{ }^{-1}, Ð=1.27\right)$ Finally, the bromide precursor copolymers were converted to the conjugated polyelectrolytes (P3HT-R) by treatment with 1-methyl-imidazole, trimethylamine and trimethylphosphine leading respectively to polymers P3HT-Im (Poly(3-[N-(1'-methylimidazolium-3-yl)hexyl]thiophene-2,5-diyl bromide), $\quad$ P3HT-NMe 3 (Poly(3-[6'-trimethylammonium)hexyl]thiophene-2,5-diyl bromide)) and P3HT-PMe 3 (Poly(3-[6'-trimethylphosphonium)hexyl]thiophene-2,5-diyl bromide)). Poly(3,4-ethylenedioxythiophene):polystyrene sulfonate (PEDOT:PSS) aqueous solutions (Clevios PH) were purchased from Heraeus. Sodium chloride $(99,5 \%)$ and barium chloride (>99\%) salts were purchased from Sigma-Aldrich. 


\section{Multilayer film characterization.}

The growth of (P3HT-R/PEDOT:PSS) multilayer film was monitored in situ using an homemade optical fixed-angle reflectometer [40]. Normalized reflectometry output $\left(\Delta \mathrm{S} / \mathrm{S}_{0}\right)$ is semi-quantitatively proportional to the adsorbed amount of polymer $\left(\mathrm{mg} \cdot \mathrm{m}^{-2}\right)$. Oxidized silicon wafers $\left(105 \pm 0.5 \mathrm{~nm}\right.$ of $\left.\mathrm{SiO}_{2}\right)$ were used as substrate after cleaning with piranha solution. The transmission UV-Vis spectra of polymer films adsorbed onto glass substrates were recorded on a Perkin Elmer Lambda 35 spectrometer. The surface morphology of polymer films was investigated, without any metallization, using a high-resolution scanning electron microscope (SEM) Quanta $450 \mathrm{~W}$ from FEI with an electron beam energy of $5 \mathrm{keV}$. Thickness of each film was then measured with a profilometer (VEECO, Model Dektak 150) equipped with a diamond stylus having a $12.5 \mu \mathrm{m}$ tip radius. Electrical conductivity of the films was investigated using the van der Pauw technique. Four contacts were realized by pressing probes made of nickel coated by a thin layer of gold. Using the same system, Seebeck effect (thermoelectric effect) was monitored by measuring electrical voltage between two probes resulting from an applied temperature gradient. A part of the substrate coated by the multilayer film was placed onto a stage maintained at $20^{\circ} \mathrm{C}$ during all the experiment and the other part was placed onto a heating holder. Temperature of the hot point was progressively increased and the resulting voltage between the two probes was measured in view of obtaining the seebeck coefficient.

\section{Results and Discussion}

Multilayer film growth: in situ investigations. Before measuring film intrinsic properties, the growth of multilayer films based on cationic CPEs P3HT-R and the negative (PEDOT:PSS) ${ }^{-} \mathrm{Na}^{+}$complex was investigated using optical reflectometry. Ionic strength (I) of polyelectrolyte solutions was fixed at $0.003 \mathrm{M}$ and $\mathrm{pH}$ was adjusted at 5.5. After the injection 
during 5 min of a polymer free solution, a P3HT-R solution was injected during 10 min leading to an increase of the reflectometry output (Figure 1) and thus, indicating the adsorption of P3HT-R onto silicon oxide substrate. This adsorption is due to electrostatic interactions operating between cationic side groups of P3HT-R and negative charges on the silicon oxide surface. Indeed, based on the isoelectric $\mathrm{pH}_{\mathrm{pzc}}(1-2)$ of silicic acid $\left(\mathrm{Si}(\mathrm{OH})_{4}\right)$, at pH 5.5, silanol groups $(\mathrm{SiOH})$ become deprotonated to form silanolate species $\left(\mathrm{SiO}^{-}\right)$[41]. Due to charge overcompensation by $\mathrm{P} 3 \mathrm{HT}-\mathrm{R}^{+}$, the surface becomes then positively charged allowing its association with (PEDOT:PSS) in the subsequent injection step. Actually, when PEDOT:PSS solution was injected, $\Delta \mathrm{S} / \mathrm{S}_{0}$ increases and reaches a plateau (Figure 1). The strong association of PEDOT:PSS with P3HT-R could be due to the combination of two types of interactions: the electrostatic interactions between the positive charges of P3HT-R and negative sulfonate groups of PSS, and the $\pi$-stacking interactions operating between the aromatic cycles of each type of polyelectrolytes. The growth of the multilayer films (Figure 1) was monitored until the substrate was coated by five bilayers (P3HT-R/PEDOT:PSS) 5 . No effect of the cationic side groups (Im, $\mathrm{NMe}_{3}, \mathrm{PMe}_{3}$ ) was noticed whatever the type of salt employed to fix the ionic strength during the film growth. This latter is more sensitive to the molecular weight of the polymer [42, 43]. In our case, since all the P3HT-based CPEs exhibit the same molecular weight, similar sizes in water are expected and thus, explains why no effect of the ionic side groups onto the film growth is noticed.

Type of salt $\left(\mathrm{Na}^{+}\right.$or $\left.\mathrm{Ba}^{2+}\right)$ was also modified according to our previous studies focused on the growth of multilayer film made of poly(diallyldimethylammonium chloride) (PDDA) and PEDOT:PSS [44]. As for (PDDA/PEDOT:PSS $)_{n}$ film, multilayer prepared using barium chloride salt exhibits an higher adsorbed amount demonstrating the effect of $\mathrm{Ba}^{2+}$ ions. By screening the negative charge of sulfonate groups, the formation of the electrostatic barrier is delayed, increasing the adsorbed amount of PEDOT:PSS. These results are consistent with 
previous studies showing that multivalent ions usually act as adsorption promoter [45]. The main driving force for the build-up of (P3HT-R/PEDOT:PSS) film is unambiguously electrostatic interactions because of the significant effect of divalent ions.

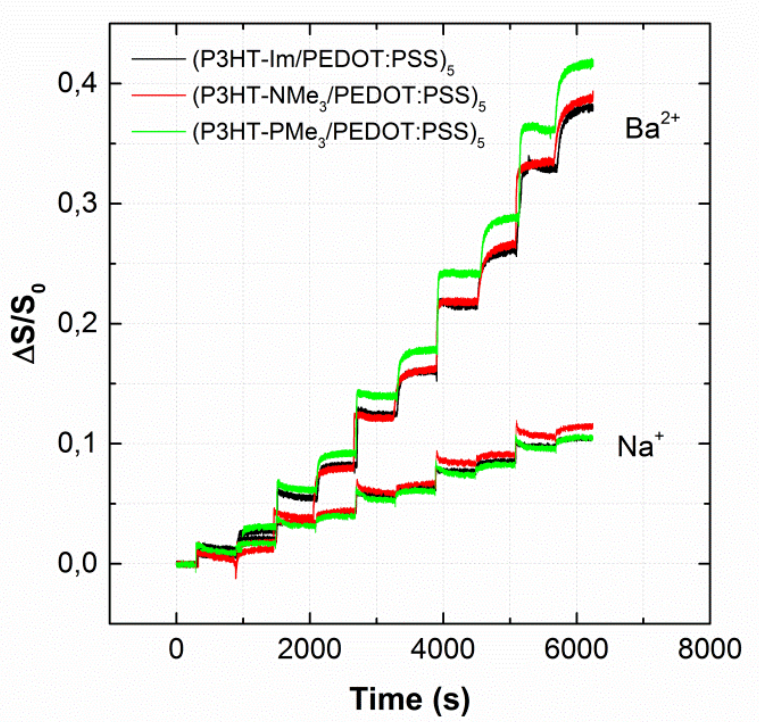

Figure 1: Reflectometry output as a function of time during P3HT-R/PEDOT:PSS multilayer formation for different ions $\left(\mathrm{Ba}^{2+}, \mathrm{Na}^{+}\right)$and different $\mathrm{R}$ side P3HT groups (-Im, - $\mathrm{NMe}_{3}$, $\mathrm{PMe}_{3}$ ). Polyelectrolyte concentration $=0.01 \mathrm{~g} \cdot \mathrm{L}^{-1}, \mathrm{pH}=5.5, \mathrm{I}=0.003 \mathrm{M}$.

In order to determine the type of multilayer growth regime (linear or exponential), the adsorbed amount of cationic and anionic polymer for each adsorption step was calculated from the data of the Figure 1 and are plotted in Figure 2. For multilayer build-up using $\mathrm{NaCl}$, the adsorbed amounts of polyelectrolytes P3HT-Im and PEDOT:PSS are constant whereas when $\mathrm{BaCl}_{2}$ is used, $\Delta \mathrm{S} / \mathrm{S}_{0}$ increases at each adsorption indicating a clear change of growth regime. With $\mathrm{Na}^{+}$ions, the multilayer grows in a linear regime while an exponential regime appears in the presence of $\mathrm{Ba}^{2+}$. This type of growth is due to an in and out diffusion process of at least one of the two polyelectrolytes used in the film construction [46]. We suggest that the polyelectrolyte which diffuses may be P3HT-Im for two reasons. First, the size of this 
cationic CPE is very small $\left(\mathrm{Mn} \sim 13500\right.$ g. $\left.\mathrm{mol}^{-1}\right)$ compared to PEDOT:PSS. Then, the screening of PSS negative charge by $\mathrm{Ba}^{2+}$ embedded in the film can facilitate the diffusion of P3HT-Im into the multilayer film.

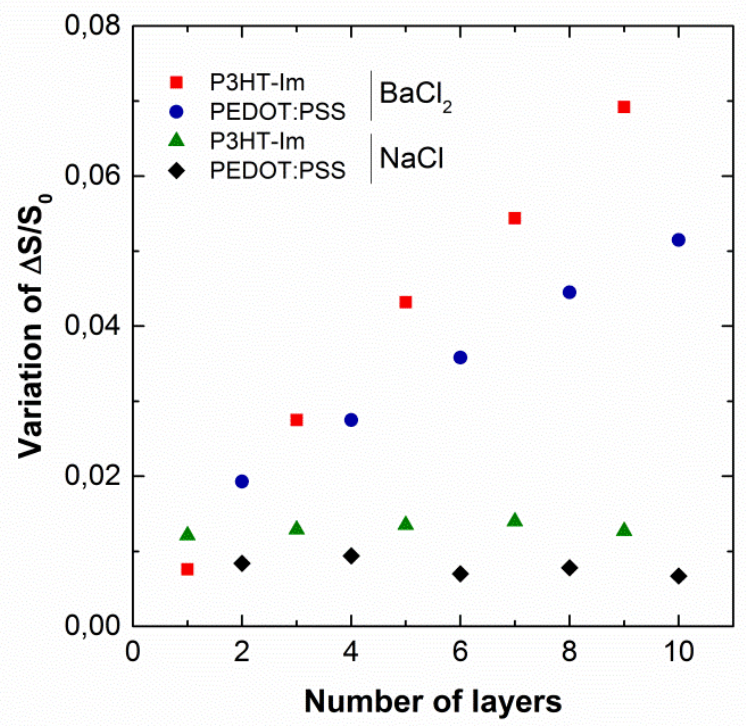

Figure 2: Values of reflectometry output $\left(\Delta \mathrm{S} / \mathrm{S}_{0}\right)$ at the plateau for each polymer adsorption step as a function of the number of layers for a (P3HT-Im/PEDOT:PSS $)_{5}$ multilayer film. Polyelectrolyte concentration $=0,01 \mathrm{~g} \cdot \mathrm{L}^{-1}, \mathrm{pH}=5.5,[\mathrm{NaCl}]=0.003 \mathrm{M},\left[\mathrm{BaCl}_{2}\right]=0.001 \mathrm{M}$.

Film properties: Process modification and side group effect.

Two multilayer build-up processes were tested: one including a rinsing step between each polyelectrolyte adsorption and a second without. This modified process was tested for the adsorption of 10 and 20 (P3HT-R/PEDOT:PSS) bilayers. The thicknesses of (P3HTR/PEDOT:PSS) multilayer film were then determined by profilometry. 


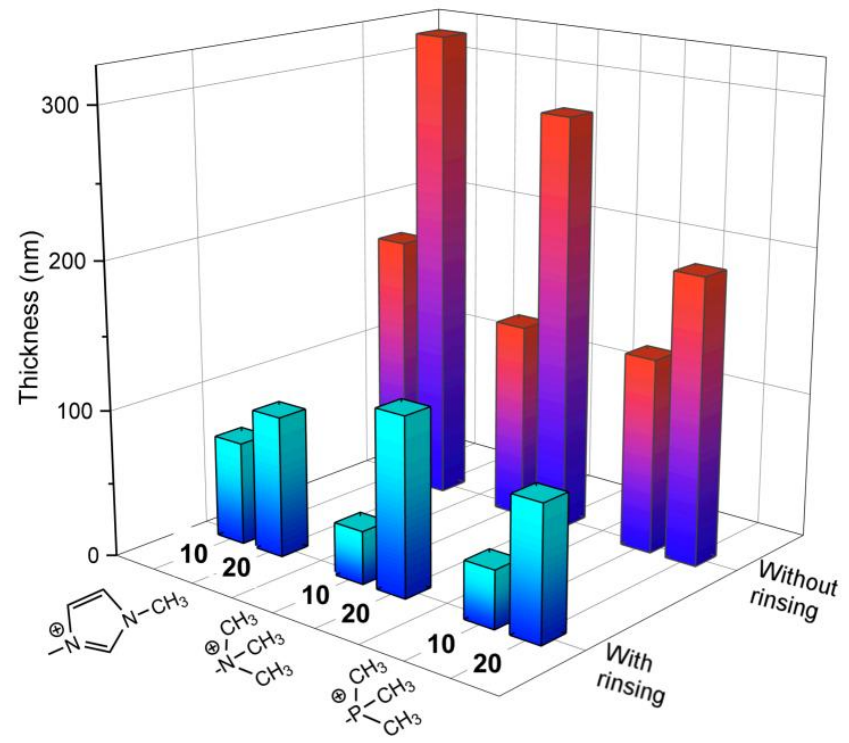

Figure 3: (P3HT-R/PEDOT:PSS) film thickness as a function of: (i) the ionic side group (Im, $\mathrm{NMe}_{3}, \mathrm{PMe}_{3}$ ), (ii) the number of adsorbed bilayers, (iii) the addition of a rinsing step during the build-up. $[\mathrm{P} 3 \mathrm{HT}-\mathrm{R}]=0.1 \mathrm{~g} \cdot \mathrm{L}^{-1},[\mathrm{PEDOT}: \mathrm{PSS}]=1 \mathrm{~g} \cdot \mathrm{L}^{-1}, \mathrm{pH}=5.5,\left[\mathrm{BaCl}_{2}\right]=0.001 \mathrm{M}$.

As shown in Figure 3, a clear effect of the process on the film thickness was noticed. Indeed, film thickness increased significantly when the rinsing step is not applied. When the substrate is rinsed, weakly adsorbed polyelectrolyte chains are removed leading to a decrease of the thickness [47]. The type of the P3HT side group seems to slightly affect the film thickness (around 50 to $100 \mathrm{~nm}$ ) for rinsed substrate. On the contrary, when 20 bilayers of (P3HTR/PEDOT:PSS) are deposited without rinsing, film thickness varied from $195 \pm 10 \mathrm{~nm}$ for P3HT-PMe 3 to $324 \pm 160 \mathrm{~nm}$ for P3HT-Im. Such difference may be explained by different film (P3HT-R/PEDOT:PSS) density for these two CPEs. Reflectometry is sensitive to the optical mass which is equal to $\Delta n \times d$ where $\Delta n$ is the variation of the refractive index and $d$ the film thickness. Since the optical mass (adsorbed amount) is the same for the three cationic P3HT-R, an increase of thickness implies a decrease of refractive index and thus, film density. As such, the film density (i.e refractive index) increases for multilayer incorporating P3HT-R 
in the following trend: P3HTIm $<$ P3HT-NMe $3<$ P3HT-PMe . This is consistent with the surface morphology obtained by SEM analysis in Figure 4 which show a progressive smoothing from P3HT-Im, P3HT-NMe 3 to P3HT-PMe 3 .
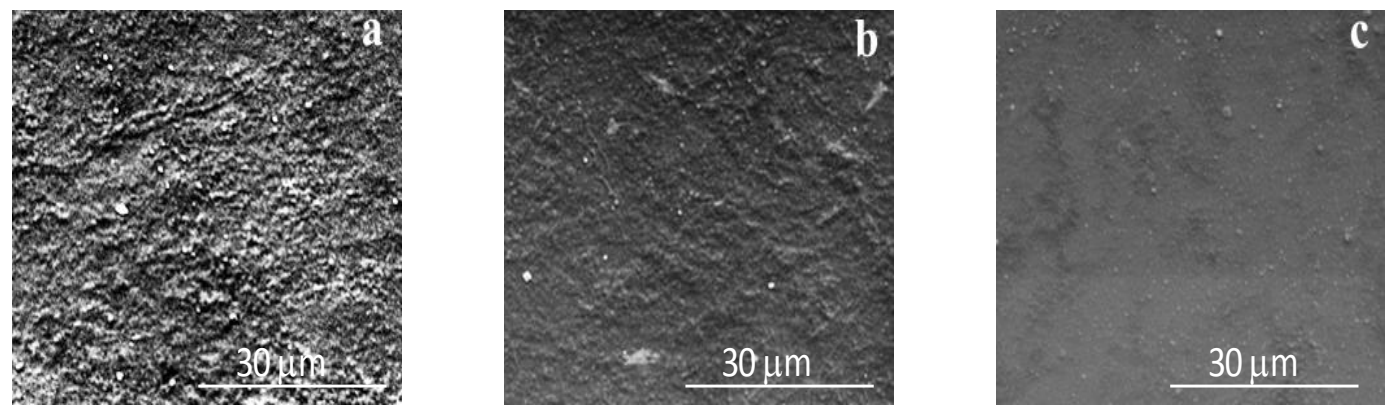

Figure 4: SEM images of multilayer films made of: a) (P3HT-Im/PEDOT:PSS) ${ }_{20}$, b) (P3HT$\left.\left.\mathrm{NMe}_{3} / \mathrm{PEDOT}: \mathrm{PSS}\right)_{20}, \mathrm{c}\right)(\mathrm{P} 3 \mathrm{HT}-\mathrm{PMe} / \mathrm{PEDOT}: \mathrm{PSS})_{20}$.

The optical properties of (P3HT-R/PEDOT:PSS) multilayer films depicted in Figure 3 were then analyzed by UV-vis absorption spectroscopy. Their absorption spectrum show two bands at $450 \mathrm{~nm}$ and $930 \mathrm{~nm}$ corresponding respectively to P3HT-R [48] PEDOT:PSS. [49] (See Supporting Information, Figure A). Absorbance of P3HT-R and PEDOT:PSS embedded into the polyelectrolyte film increases linearly as a function of the film thickness independently from the nature of the side group. Such linear relationship indicates a well-controlled accumulation of the electrostatic LbL films and a homogeneous distribution of PEDOT:PSS and P3HT-R CPEs inside the film.

\section{Electrical conductivity and activation energy}

Using data extracted from the van der Pauw technique, the electrical conductivity of each (P3HT/PEDOT:PSS) LbL system was measured. Note that no rinsing step was applied during film preparation in order to rapidly produce thick films. Values of conductivity are summarized in Table 1. For the other LbL films e.g. shown in Figure 3, no conductivity was determined (films were too much resistive). Indeed, the value of conductivity wasn't 
calculated due a poor correlation between the recorded tensions and intensities[50]. Conductivity increases with the temperature showing the semiconducting-like behavior of these LbL films. At $150{ }^{\circ} \mathrm{C}$, the films containing P3HT-Im and P3HT-PMe 3 exhibit a conductivity of $3{\mathrm{~S} . \mathrm{m}^{-1}}^{\text {while the conductivity is } 5 \mathrm{~S}^{-1} \mathrm{~m}^{-1} \text { for P3HT-NMe}}$-based film. The association of these two conductive polyelectrolytes in LbL films allows achieving a conductivity superior to that of multilayer film made of a conductive polyelectrolyte and an insulating polyelectrolyte [44, 51]. For (P3HT-NMe 3 /PEDOT:PSS) film, conductivity does not depend on the film thickness e.g. for the number of adsorbed bilayers. This indicates that film is homogenous and each polyelectrolyte is well distributed into the film.

\begin{tabular}{ccccccccccc}
\hline & & Thickness & \multicolumn{5}{c}{ Conductivity (S.m ${ }^{-1}$ ) } \\
\cline { 4 - 9 } P3HT side group & $\mathbf{N}$ & $(\mathbf{n m})$ & $30^{\circ} \mathrm{C}$ & $50^{\circ} \mathrm{C}$ & $100^{\circ} \mathrm{C}$ & $150^{\circ} \mathrm{C}$ & $100^{\circ} \mathrm{C}$ & $50^{\circ} \mathrm{C}$ & $30^{\circ} \mathrm{C}$ \\
\hline $\mathrm{Im}$ & 20 & 324 & 1.50 & 1.93 & 2.88 & 3.34 & 2.91 & 2.70 & 2.19 \\
$\mathrm{NMe}_{3}$ & 10 & 134 & 2.46 & 3.10 & 4.20 & 5.02 & 4.23 & 3.33 & 3.95 \\
$\mathrm{NMe}_{3}$ & 20 & 283 & 2.19 & 2.80 & 4.33 & 5.39 & 4.62 & 3.39 & 2.63 \\
$\mathrm{PMe}_{3}$ & 20 & 195 & - & - & 2.97 & 3.14 & 3.33 & - & - \\
\hline
\end{tabular}

Table 1: Conductivity of (P3HT-R/PEDOT:PSS $)_{\mathrm{n}}$ films as a function of: (1) the ionic side group, (2) the number of bilayers (N) and (3) the temperature.

Due to the P3HT-R/PEDOT:PSS film semiconductive properties which is thermally activated, Arrhenius model can be used to calculate the activation energy. Consequently, from the slopes of the variation of $\ln \sigma$ with the reciprocal temperature (Figure 5), the activation energies (Ea) were calculated. Whatever the nature of stacked polyelectrolytes, the activation energy was the same and was equal to $72 \pm 2 \mathrm{meV}$. This low value correlates with materials containing electrons as free carriers. Indeed, an electronic conduction process is characterized by an 
activation energy of few tens of meV [52]. Once again, the nature of side groups of P3HT does not affect the electronic conduction mechanism.

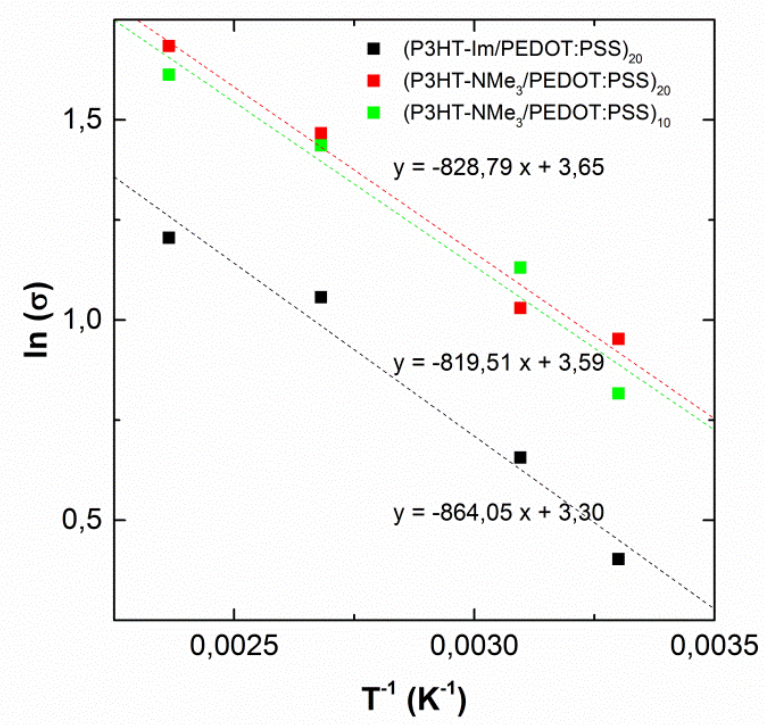

Figure 5: Arrhenius plot for P3HT-R/PEDOT:PSS multilayer films. [P3HT-R] $=0.1$ g.L $\mathrm{L}^{-1}$, $[$ PEDOT:PSS $]=1$ g.L ${ }^{-1}, \mathrm{pH}=5.5,\left[\mathrm{BaCl}_{2}\right]=0.001 \mathrm{M}$.

\section{Type of charge carrier: Seebeck effect}

In order to determine the $\mathrm{n}$ or $\mathrm{p}$ type character of the semiconductor multilayer film, samples were placed between two heating plates. Seebeck effect reveals if an induced thermoelectric voltage is recorded when a temperature difference across the sample is applied. Before analysing multilayer films, drop casting of P3HT-R and PEDOT:PSS were carried out to prepare a thick film of each polyelectrolyte. Variation of the tension as a function of the temperature's gradient is plotted in Figure 6. Results show a linear increase of the tension indicating that the charge carrier is p-type for both films. Same experiments were then performed using LbL film. In all cases, the slope was positive indicating that(P3HTR/PEDOT:PSS $)_{n}$ films are p-type semiconductor material and conduction is ensured by positive charges (holes). 
Seebeck coefficients e.g. values of the slope, are summarized in Table 2. For drop casted films, Seebeck coefficient is equal to $1200 \mu \mathrm{V} \cdot \mathrm{K}^{-1}$ for P3HT-Im and to $26.0 \mu \mathrm{V} . \mathrm{K}^{-1}$ for PEDOT:PSS. These coefficients are in agreement with those reported in the literature [53-55]. For multilayer films, the Seebeck coefficient is between the coefficients of drop casted films. A lower value was found for (P3HT-Im/PEDOT:PSS $)_{n}$ film. This could be explained by the presence of imidazole ring. Indeed, $\pi$-staking interaction between imidazole ring and either styrene or thiophene ring could modify the conduction. Seebeck coefficient values may vary from $-100 \mu \mathrm{V} . \mathrm{K}^{-1}$ to $+1000 \mu \mathrm{V} \cdot \mathrm{K}^{-1}$. For (P3HT-Im/PEDOT:PSS) $)_{\mathrm{n}}$, due to the value of Seebeck coefficient, potential applications can be found for systems based on thermoelectric effect. Finally, by controlling the amount of P3HT-Im and PEDOT:PSS into the multilayer, Seebeck coefficient of the films could be adjusted to a required value for a specific application.
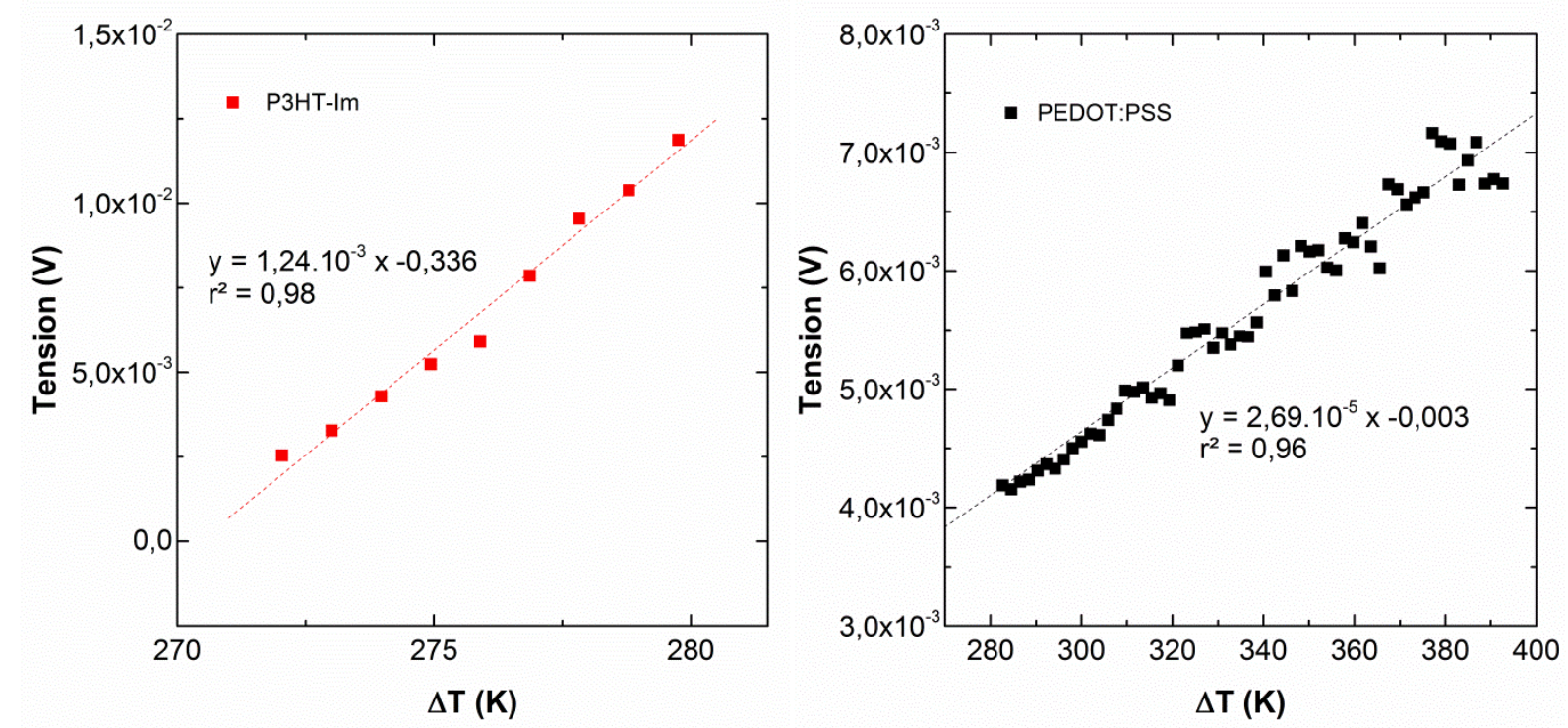

Figure 6: Variation of the tension as a function of the temperature's gradient for: a) Drop casted film of P3HT-Im and b) Drop casted film of PEDOT:PSS. 


\begin{tabular}{cc}
\hline Film system & $\begin{array}{c}\text { Seebeck Coefficient } \\
\left(\boldsymbol{\mu} \mathbf{V} \cdot \mathbf{K}^{-\mathbf{1}}\right)\end{array}$ \\
\hline Pure P3HT-Im & 1200 \\
Pure PEDOT:PSS & 26 \\
\hline$(\text { P3HT-Im/PEDOT:PSS })_{20}$ & 219 \\
$($ P3HT-NMe & /PEDOT:PSS $)_{20}$ \\
$(\text { P3HT-PMe } / \text { PEDOT:PSS })_{20}$ & 262 \\
\hline
\end{tabular}

Table 2: Seebeck coefficients of multilayer films. [P3HT-R] $=0.1$ g. $\mathrm{L}^{-1}$, [PEDOT:PSS] $=1$ g. $\mathrm{L}^{-1}, \mathrm{pH}=5.5,[\mathrm{NaCl}]=0.003 \mathrm{M}$.

\section{Electrical conductivity of $\mathrm{LbL}$ films on flexible substrate}

(P3HT-Im/PEDOT:PSS) 20 multilayer was deposited onto a flexible polyvinyl chloride (PVC) sheet with a thickness of $0.15 \mathrm{~mm}$. Substrates $(40 \mathrm{~mm} \times 25 \mathrm{~mm})$ were cleaned by dipping in ethanol and rinsed with ultrapure water. After functionalization, sample was placed between the jaws of a vice (See Supporting Information, Figure B). Four copper wires were then glutted on the top of multilayer film using silver-filled electro conductive coating substance (Ecolit 342) and connected to the van der Pauw apparatus. Finally, by rotating the screw that connects both jaws, PVC sheet was progressively curved with a radius of curvature ranging from $+\infty$ to $6.0 \mathrm{~mm}$ (See Supporting Information, Figure B). Conductivity of (P3HTIm/PEDOT:PSS $)_{20}$ films prepared with $\mathrm{NaCl}$ or $\mathrm{BaCl}_{2}$ at same ionic strength was measured at $25{ }^{\circ} \mathrm{C}$ (Table 3 ) as a function of the radius of curvature. In all cases, the conductivity was not modified even for a high bending stress. The structure of the films resists to the applied physical force. Moreover, conductivity is the same whatever the salt used as electrolyte. Ions embedded in the film namely sodium or barium cations do not disturb the conductivity for a low bending stress as well as a high bending stress. Consequently, valence of ions only affects 
the growth of the film as shown by the difference of film thickness $(110 \mathrm{~nm}$ for $\mathrm{NaCl}$ and 295 nm for $\mathrm{BaCl}_{2}$ )

\begin{tabular}{ccc}
\hline $\begin{array}{c}\text { Radius of curvature } \\
(\mathbf{m m})\end{array}$ & $\mathrm{NaCl}$ & $\begin{array}{c}\text { Conductivity } \\
\left(\mathbf{S}^{-\mathbf{1}}\right)\end{array}$ \\
\hline$\infty$ & 1.15 & $\mathrm{BaCl}_{2}$ \\
\hline 16.9 & 1.22 & 1.20 \\
13.0 & 1.27 & 1.13 \\
10.3 & 1.40 & 1.21 \\
8.6 & 1.74 & 1.15 \\
7.5 & 1.71 & 1.20 \\
6.7 & 1.27 & 1.17 \\
6.3 & 1.28 & 1.07 \\
6.0 & 1.43 & 1.21 \\
\hline
\end{tabular}

Table 3: Conductivity as a function of the radius of curvature for (P3HT-Im/PEDOT:PSS $\left.{ }_{\mathrm{PH}}\right)_{20}$ multilayer films, $\left[\right.$ P3HT-R] $=0.1$ g. $\mathrm{L}^{-1}$, PEDOT:PSS $]=1 \mathrm{~g} . \mathrm{L}^{-1}, \mathrm{pH}=5.5$, Ionic strength $=$ $0.001 \mathrm{M}$ at $20^{\circ} \mathrm{C}$. 


\section{Conclusions}

Multilayered films were successfully prepared from cationic P3HT-based CPEs bearing different ionic side groups and anionic PEDOT:PSS by using electrostatic LbL assembly. The growth of the (P3HT-R/PEDOT:PSS) LbL films was found to be not dependent of the nature of the P3HT ionic side group as shown by in situ reflectometry analysis. On the contrary, the valence of the electrolyte ions was identified as a key parameter influencing the film growth since adsorbed amount of each polyelectrolyte increases when monovalent ions $\left(\mathrm{Na}^{+}\right)$used to fix the ionic strength are replaced by divalent ions $\left(\mathrm{Ba}^{2+}\right)$. Similarly, the film thickness increases when the rinsing step between each polyelectrolyte adsorption is removed.

Electrical properties of thin P3HT-R/PEDOT:PSS multilayered films were then investigated. Film prepared using $\mathrm{P} 3 \mathrm{HT}-\mathrm{NMe}_{3}$ was more conductive than those produced using P3HT$\mathrm{PMe}_{3}$ or P3HT-Im. Films Conductivity increases with temperature demonstrating a semiconducting-like behavior of the LbL films with the same activation energy for the three P3HT-R/PEDOT:PSS films. This value of activation energy indicates that the conductivity in these organic materials is electronic. Then, the Seebeck measurements allow determining that P3HT-R/PEDOT:PSS multilayered films are $p$-type organic semiconductors.

Finally, P3HT-R/PEDOT:PSS multilayers were deposited onto a PVC flexible sheet. It was shown that conductivity is not affected by applying a bending stress on the PVC sheet. As such, these hybrid films can be exploited in deformable thermoelectronic devices and more specifically, in flexible organic electrics such as an hole transporting layer in OLEDs or as cathode interface materials in solar cells. 


\section{Supplementary materials:}

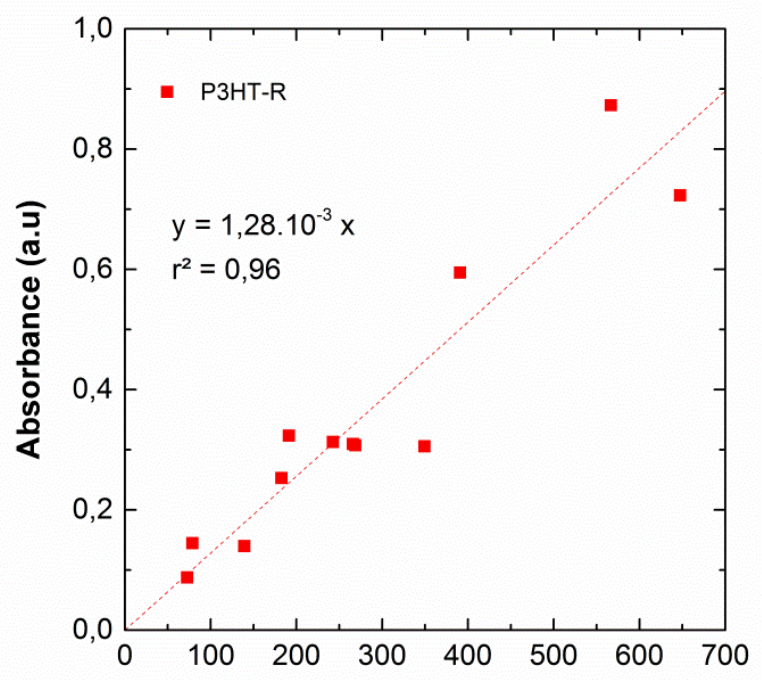

a)

Thickness $(\mathrm{nm})$

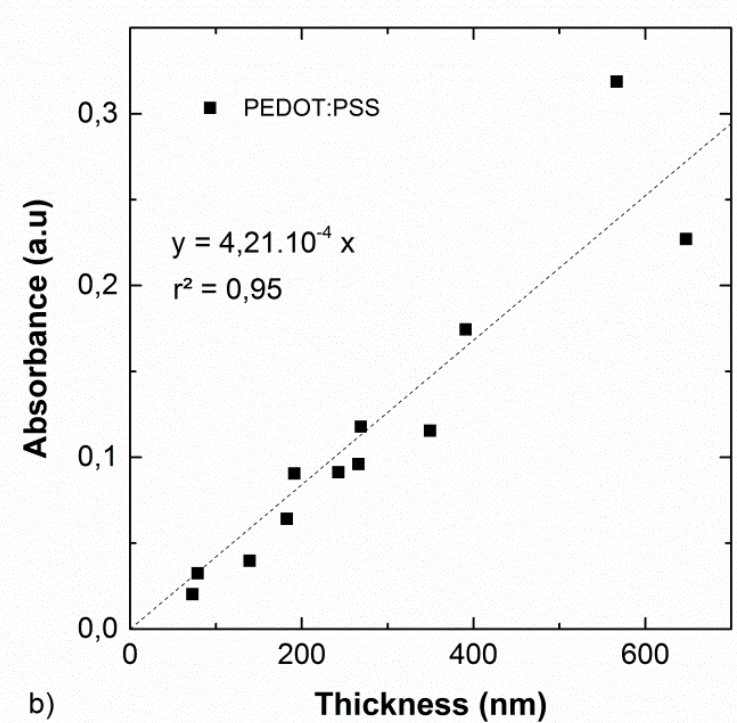

Figure A: Absorbance values of P3HT-R and PEDOT:PSS from (P3HT-R/PEDOT:PSS) multilayer films as a function of their thickness. a) $450 \mathrm{~nm}$ for P3HT-R, b) $930 \mathrm{~nm}$ for PEDOT:PSS.

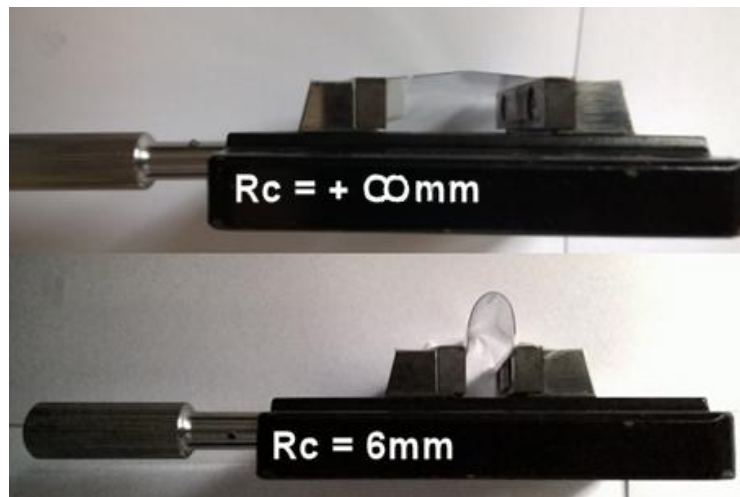

Figure B: Experimental set-up for film conductivity measurements as a function of the radius of curvature $\left(\mathrm{R}_{\mathrm{c}}\right)$. 


\section{References}

[1] B. Liu, G.C. Bazan, Conjugated Polyelectrolytes: Fundamentals and Applications, Wiley-VCH Verlag GmbH \& Co. KGaA, Weinheim, 2013.

[2] J. Liang, K. Li, B. Liu, Visual sensing with conjugated polyelectrolytes, Chemical Science, 4 (2013) 1377-1394.

[3] S. Das, P. Routh, R. Ghosh, D.P. Chatterjee, A.K. Nandi, Water-soluble ionic polythiophenes for biological and analytical applications, Polymer International, (2016) 5295.

[4] C. Zhu, L. Liu, Q. Yang, F. Lv, S. Wang, Water-Soluble Conjugated Polymers for Imaging, Diagnosis, and Therapy, Chemical Reviews, 112 (2012) 4687-4735.

[5] G. Feng, D. Ding, B. Liu, Fluorescence bioimaging with conjugated polyelectrolytes, Nanoscale, 4 (2012) 6150-6165.

[6] C. Duan, K. Zhang, C. Zhong, F. Huang, Y. Cao, Recent advances in water/alcohol-soluble [small pi]-conjugated materials: new materials and growing applications in solar cells, Chemical Society Reviews, 42 (2013) 9071-9104.

[7] W. Lee, J.H. Seo, H.Y. Woo, Conjugated polyelectrolytes: A new class of semiconducting material for organic electronic devices, Polymer, 54 (2013) 5104-5121.

[8] Z. Hu, K. Zhang, F. Huang, Y. Cao, Water/alcohol soluble conjugated polymers for the interface engineering of highly efficient polymer light-emitting diodes and polymer solar cells, Chemical Communications, 51 (2015) 5572-5585.

[9] T.-Q. Nguyen, R.C. Kwong, M.E. Thompson, B.J. Schwartz, Improving the performance of conjugated polymer-based devices by control of interchain interactions and polymer film morphology, Applied Physics Letters, 76 (2000) 2454-2456.

[10] R.C. Evans, Harnessing self-assembly strategies for the rational design of conjugated polymer based materials, Journal of Materials Chemistry C, 1 (2013) 4190-4200.

[11] L. Xu, L. Yang, S. Lei, Self-assembly of conjugated oligomers and polymers at the interface: structure and properties, Nanoscale, 4 (2012) 4399-4415.

[12] M. Knaapila, R.C. Evans, V.M. Garamus, L. Almásy, N.K. Székely, A. Gutacker, U. Scherf, H.D. Burrows, Structure and "Surfactochromic" Properties of Conjugated Polyelectrolyte (CPE): Surfactant Complexes between a Cationic Polythiophene and SDS in Water, Langmuir, 26 (2010) 15634-15643.

[13] A. Gutacker, N. Koenen, U. Scherf, S. Adamczyk, J. Pina, S.M. Fonseca, A.J.M. Valente, R.C. Evans, J. Seixas de Melo, H.D. Burrows, M. Knaapila, Cationic fluorene-thiophene diblock copolymers: Aggregation behaviour in methanol/water and its relation to thin film structures, Polymer, 51 (2010) 1898-1903.

[14] P. Urbánek, A. di Martino, S. Gladyš, I. Kuřitka, A. Minařík, E. Pavlova, D. Bondarev, Polythiophene-based conjugated polyelectrolyte: Optical properties and association behavior in solution, Synthetic Metals, 202 (2015) 16-24.

[15] H. Jiang, X. Zhao, K.S. Schanze, Amplified Fluorescence Quenching of a Conjugated Polyelectrolyte Mediated by Ca2+, Langmuir, 22 (2006) 5541-5543.

[16] H.D. Burrows, S.M. Fonseca, F.B. Dias, J.S. de Melo, A.P. Monkman, U. Scherf, S. Pradhan, Singlet Excitation Energy Harvesting and Triplet Emission in the Self-Assembled System Poly $\{1,4-$ phenylene-[9,9-bis

(4-phenoxy-butylsulfonate)]fluorene-2,7-diyl

copolymer/tris(bipyridyl)ruthenium(II)in Aqueous Solution, Advanced Materials, 21 (2009) 11551159.

[17] H.D. Burrows, T. Costa, M.L. Ramos, A.J.M. Valente, B. Stewart, L.L.G. Justino, A.I.A. Almeida, N.L. Catarina, R. Mallavia, M. Knaapila, Self-assembled systems of water soluble metal 8hydroxyquinolates with surfactants and conjugated polyelectrolytes, Physical Chemistry Chemical Physics, 18 (2016) 16629-16640.

[18] J.E. Houston, A.R. Patterson, A.C. Jayasundera, W. Schmitt, R.C. Evans, Charge-modulated selfassembly and growth of conjugated polyelectrolyte-polyoxometalate hybrid networks, Chemical Communications, 50 (2014) 5233-5235.

[19] J. Rubio-Magnieto, E.G. Azene, J. Knoops, S. Knippenberg, C. Delcourt, A. Thomas, S. Richeter, A. Mehdi, P. Dubois, R. Lazzaroni, D. Beljonne, S. Clement, M. Surin, Self-assembly and hybridization mechanisms of DNA with cationic polythiophene, Soft Matter, 11 (2015) 6460-6471. 
[20] J. Rubio-Magnieto, A. Thomas, S. Richeter, A. Mehdi, P. Dubois, R. Lazzaroni, S. Clement, M. Surin, Chirality in DNA-[small pi]-conjugated polymer supramolecular structures: insights into the self-assembly, Chemical Communications, 49 (2013) 5483-5485.

[21] R.C. Evans, M. Knaapila, N. Willis-Fox, M. Kraft, A. Terry, H.D. Burrows, U. Scherf, Cationic Polythiophene-Surfactant Self-Assembly Complexes: Phase Transitions, Optical Response, and Sensing, Langmuir, 28 (2012) 12348-12356.

[22] Y.-J. Jin, J.-H. Yoon, T. Sakaguchi, C.-L. Lee, G. Kwak, Highly Emissive, Water-Repellent, Soft Materials: Hydrophobic Wrapping and Fluorescent Plasticizing of Conjugated Polyelectrolyte via Electrostatic Self-Assembly, Advanced Functional Materials, 26 (2016) 4501-4510.

[23] W.-E. Lee, Y.-J. Jin, B.S.-I. Kim, G. Kwak, T. Sakaguchi, H.H. Lee, J.H. Kim, J.S. Park, N. Myoung, C.-L. Lee, In-Situ Electrostatic Self-Assembly of Conjugated Polyelectrolytes in a Film, Advanced Materials Interfaces, 1 (2014) n/a-n/a.

[24] T. Costa, A.T. Marques, J.S. Seixas de Melo, A.W. Thomas, L.E. Garner, U. Scherf, G.C. Bazan, H.D. Burrows, Self-Assembly of Poly\{1,4-phenylene-[9,9-bis(4-phenoxy-butylsulfonate)]fluorene2,7-diyl $\}$ with Oppositely Charged Phenylenevinylene Oligoelectrolytes, The Journal of Physical Chemistry B, 118 (2014) 613-623.

[25] G. Decher, Fuzzy nanoassemblies: toward layered polymeric multicomposites, Science, 277 (1997) 1232-1237.

[26] P. Bertrand, A. Jonas, R. Legras, Ultrathin polymer coatings by complexation of polyelectrolytes at interfaces: Suitable materials, structure, and properties., Macromolecular Rapid Communications, $21(2000) 319$.

[27] J. Tian, M.E. Thompson, C.-C. Wu, J.C. Sturm, R.A. Register, M.J. Marsella, T.M. Swager, Electroluminescent properties of self-assembled polymer thin films, Advanced Materials, 7 (1995) 395-398.

[28] J.W. Baur, S. Kim, P.B. Balanda, J.R. Reynolds, M.F. Rubner, Thin-Film Light-Emitting Devices Based on Sequentially Adsorbed Multilayers of Water-Soluble Poly(p-phenylene)s, Advanced Materials, 10 (1998) 1452-1455.

[29] D.A. Rider, B.J. Worfolk, K.D. Harris, A. Lalany, K. Shahbazi, M.D. Fleischauer, M.J. Brett, J.M. Buriak, Stable Inverted Polymer/Fullerene Solar Cells Using a Cationic Polythiophene Modified PEDOT:PSS Cathodic Interface, Advanced Functional Materials, 20 (2010) 2404-2415.

[30] B.J. Worfolk, T.C. Hauger, K.D. Harris, D.A. Rider, J.A.M. Fordyce, S. Beaupré, M. Leclerc, J.M. Buriak, Work Function Control of Interfacial Buffer Layers for Efficient and Air-Stable Inverted Low-Bandgap Organic Photovoltaics, Advanced Energy Materials, 2 (2012) 361-368.

[31] K. Zhang, Z. Hu, R. Xu, X.-F. Jiang, H.-L. Yip, F. Huang, Y. Cao, High-Performance Polymer Solar Cells with Electrostatic Layer-by-Layer Self-Assembled Conjugated Polyelectrolytes as the Cathode Interlayer, Advanced Materials, 27 (2015) 3607-3613.

[32] M. Chevrier, J.E. Houston, J. Kesters, N. Van den Brande, A.E. Terry, S. Richeter, A. Mehdi, O. Coulembier, P. Dubois, R. Lazzaroni, B. Van Mele, W. Maes, R.C. Evans, S. Clement, Self-assembled conjugated polyelectrolyte-surfactant complexes as efficient cathode interlayer materials for bulk heterojunction organic solar cells, Journal of Materials Chemistry A, 3 (2015) 23905-23916.

[33] J. Kesters, S. Govaerts, G. Pirotte, J. Drijkoningen, M. Chevrier, N. Van den Brande, X. Liu, M. Fahlman, B. Van Mele, L. Lutsen, D. Vanderzande, J. Manca, S. Clément, E. Von Hauff, W. Maes, High-Permittivity Conjugated Polyelectrolyte Interlayers for High-Performance Bulk Heterojunction Organic Solar Cells, ACS Applied Materials \& Interfaces, 8 (2016) 6309-6314.

[34] J.H. Seo, A. Gutacker, Y. Sun, H. Wu, F. Huang, Y. Cao, U. Scherf, A.J. Heeger, G.C. Bazan, Improved High-Efficiency Organic Solar Cells via Incorporation of a Conjugated Polyelectrolyte Interlayer, Journal of the American Chemical Society, 133 (2011) 8416-8419.

[35] T. Yokozawa, Y. Nanashima, Y. Ohta, Precision Synthesis of n-Type $\pi$-Conjugated Polymers in Catalyst-Transfer Condensation Polymerization, ACS Macro Letters, 1 (2012) 862-866.

[36] M.C. Stefan, M.P. Bhatt, P. Sista, H.D. Magurudeniya, Grignard metathesis (GRIM) polymerization for the synthesis of conjugated block copolymers containing regioregular poly(3hexylthiophene), Polymer Chemistry, 3 (2012) 1693-1701.

[37] I. Osaka, R.D. McCullough, Advances in Molecular Design and Synthesis of Regioregular Polythiophenes, Accounts of Chemical Research, 41 (2008) 1202-1214. 
[38] L. Zhai, R.D. McCullough, Layer-by-Layer Assembly of Polythiophene, Advanced Materials, 14 (2002) 901-905.

[39] S. Clement, A. Tizit, S. Desbief, A. Mehdi, J. De Winter, P. Gerbaux, R. Lazzaroni, B. Boury, Synthesis and characterisation of [small pi]-conjugated polymer/silica hybrids containing regioregular ionic polythiophenes, Journal of Materials Chemistry, 21 (2011) 2733-2739.

[40] N.G. Hoogeveen, M.A. Cohen Stuart, G.J. Fleer, M.R. Bohmer, Formation and stability of multilayers of polyelectrolytes, Langmuir, 12 (1996) 3675-3681.

[41] J. Persello, Surface and Interface Structure of Silicas, in: E. Papirer (Ed.) Adsorption on Silica Surfaces 1998, pp. 297- 342.

[42] J.C. Dijt, M.A. Cohen Stuart, G.J. Fleer, Competitive adsorption kinetics of polymers differing in length only, Macromolecules, 27 (1994) 3219-3228.

[43] G.J. Fleer, M.A. Cohen Stuart, J.M.H.M. Scheutjens, T. Cosgrove, B. Vincent, Polymers at Interfaces, Chapman and Hall, London, 1993.

[44] F.E. Jurin, C.C. Buron, N. Martin, C. Filiâtre, Preparation of conductive PDDA/(PEDOT:PSS) multilayer thin film: Influence of polyelectrolyte solution composition, Journal of Colloid and Interface Science, 431 (2014) 64-70.

[45] C.C. Buron, C. Filiâtre, F. Membrey, C. Bainier, L. Buisson, D. Charraut, A. Foissy, Surface morphology and thickness of a multilayer film composed of strong and weak polyelectrolytes: Effect of the number of adsorbed layers, concentration and type of salts, Thin Solid Films, 517 (2009) 2611 2617.

[46] C. Picart, J. Mutterer, L. Richert, Y. Luo, G.D. Prestwich, P. Schaaf, J.-C. Voegel, P. Lavalle, Molecular basis for the explanation of the exponential growth of polyelectrolyte multilayers, Proceedings of the National Academy of Sciences of the United States of America, 99 (2002) 12531 12535.

[47] G. Decher, J.B. Schlenoff, Multilayers thin films, Wiley-VCH, Weinheim, 2003.

[48] S. Hotta, S.D.D.V. Rughooputh, A.J. Heeger, F. Wudl, Spectroscopic studies of soluble poly(3alkylthienylenes), Macromolecules, 20 (1987) 212-215.

[49] Z. Tang, S.T. Donohoe, J.M. Robinson, P.A. Chiarelli, H.-L. Wang, Film formation, surface character, and relative density for electrochromic PEI/(PSS:PEDOT) multilayered thin films, Polymer, 46 (2005) 9043-9052.

[50] L.J. Van Der Pauw, A method of measuring the resistivity and Hall coefficient on lamellae of arbitrary shape, Philips Res. Repts, 20 (1958) 1-9.

[51] R.R. Smith, A.P. Smith, J.T. Stricker, B.E. Taylor, M.F. Durstock, Layer-by-Layer Assembly of Poly(3,4-ethylenedioxythiophene):Poly(styrenesulfonate), Macromolecules, 39 (2006) 6071-6074.

[52] F. Lévy, Physique et technologie des semiconducteurs, PPUR presses polytechniques 1995.

[53] M. He, J. Ge, Z. Lin, X. Feng, X. Wang, H. Lu, Y. Yang, F. Qiu, Thermopower enhancement in conducting polymer nanocomposites via carrier energy scattering at the organic-inorganic semiconductor interface, Energy \& Environmental Science, 5 (2012) 8351-8358.

[54] J. Luo, D. Billep, T. Waechtler, T. Otto, M. Toader, O. Gordan, E. Sheremet, J. Martin, M. Hietschold, D.R.T. Zahn, T. Gessner, Enhancement of the thermoelectric properties of PEDOT:PSS thin films by post-treatment, Journal of Materials Chemistry A, 1 (2013) 7576-7583.

[55] Z. Fan, D. Du, Z. Yu, P. Li, Y. Xia, J. Ouyang, Significant Enhancement in the Thermoelectric Properties of PEDOT:PSS Films through a Treatment with Organic Solutions of Inorganic Salts, ACS Applied Materials \& Interfaces, (2016) DOI: 10.1021/acsami.1026b07234. 